\title{
Linkage of Crohn's disease to the major histocompatibility complex region is detected by multiple non-parametric analyses
} H Yang, S E Plevy, K Taylor, D Tyan, N Fischel-Ghodsian, C McElree, S R Targan,
J I Rotter

\begin{abstract}
Background-There is evidence for genetic susceptibility to Crohn's disease, and a tentative association with tumour necrosis factor (TNF) and HLA class II alleles.

Aims-To examine the potential of genetic linkage between Crohn's disease and the MHC region on chromosome $6 \mathrm{p}$.

Methods-TNF microsatellite markers and, for some families, additional HLA antigens were typed for 323 individuals from 49 Crohn's disease multiplex families to generate informative haplotypes. Non-parametric linkage analysis methods, including sib pair and affected relative pair methods, were used.

Results-Increased sharing of haplotypes was observed in affected sib pairs: $92 \%$ (48/52) shared one or two haplotypes versus an expected $75 \%$ if linkage did not exist $(p=0.004)$. After other affected relative pairs were included, the significance level reached 0.001 . The mean proportion of haplotype sharing was increased for both concordant affected $(\pi=0.60$, $\mathrm{p}=0.002)$ and unaffected sib pairs $(\pi=0.58$, $\mathbf{p}=0.031)$ compared with the expected value $(\pi=0.5)$. In contrast, sharing in discordant sib pairs was significantly decreased $(\pi=0.42, \quad p=0.007)$. Linear regression analysis using all three types of sib pairs yielded a slope of -0.38 at $p=0.00003$. It seemed that the HLA effect was stronger in non-Jewish families than in Jewish families.

Conclusions-All available analytical methods support linkage of Crohn's disease to the MHC region in these Crohn's disease families. This region is estimated to contribute approximately $10-33 \%$ of the total genetic risk to Crohn's disease.

(Gut 1999;44:519-526)

Keywords: Crohn's disease; HLA; linkage; inflammatory bowel disease; tumour necrosis factor; genetics

Crohn's disease is one of the two major forms of chronic inflammatory bowel disease (IBD). The important role of genetic factors in the aetiology of Crohn's disease has been strongly

twins (0.44) compared with that in dizygotic twins $(0.04) .^{2}$ However, the exact genetic factors and their influence on the susceptibility of an individual to Crohn's disease are still unclear.

To date, genes within the major histocompatibility complex (MHC) region have been the most intensively studied in Crohn's disease. Genes in this complex are critical in antigen presentation and recognition and thus fundamental to the immune response. However, HLA association studies in Crohn's disease revealed somewhat confusing results, as some studies have shown positive associations with HLA genes and some have not. Even among studies that showed a positive association, different HLA alleles have been associated with Crohn's disease..$^{3-8}$ Variations in association results could conceivably be due to inadequate sample sizes, inappropriate controls, or genetic heterogeneity. However, the observation that Crohn's disease is associated with different HLA DR and DQ alleles suggests that this gene itself is unlikely to be the disease susceptibility gene, but is in linkage disequilibrium with other more specific Crohn's disease susceptibility genes within the HLA complex and that this linkage disequilibrium may vary among different populations.

Other candidate genes residing in the MHC region are the genes for tumour necrosis factor $\alpha(\mathrm{TNF}-\alpha)$ and TNF- $\beta$. Both cytokines are potent modulators of the immune response and mediators of inflammation. A central role for TNF- $\alpha$ in the pathogenesis of Crohn's disease has been shown by dramatic clinical responses following infusion of an anti-TNF- $\alpha$ monoclonal antibody (cA2, Centocor, Inc., Malvern, Pennsylvania) in open label and placebo controlled trials. ${ }^{9} 10$ Furthermore, in a case control study evaluating genetic markers at five loci flanking and within the TNF locus (TNF microsatellites), a specific TNF microsatellite haplotype, a $2 \mathrm{~b} 1 \mathrm{c} 2 \mathrm{~d} 4 \mathrm{e} 1$, was found to be associated with Crohn's disease. ${ }^{11}$ In contrast, polymorphisms of the TNF- $\alpha$ gene promoter region (TNF-308) were not associated with either Crohn's disease as a whole, ${ }^{12}$ or a subset of Crohn's disease. ${ }^{13}$

One way to evaluate the importance of the MHC region in Crohn's disease is to perform a linkage study. A linkage study asks whether a genetic marker (for example, MHC gene)
\end{abstract} supported by genetic epidemiological studies, including consistent ethnic differences, dramatic familial aggregation, ${ }^{1}$ and a significantly increased concordance rate in monozygotic
Abbreviations used in this paper: MHC, major histocompatibility complex; MZ, monozygotic; TNF, tumour necrosis factor. 
travels together with the disease (for example, Crohn's disease) in families. If a Crohn's disease susceptibility gene is located close enough to the marker gene (for example, TNF, HLA) - that is, within less than 10 million base pairs, then in a particular family, the disease phenotype and a particular marker allele will travel together from parent to offspring, although in different families there may be different marker alleles travelling together with the disease. Thus, a genetic linkage study will help clarify the potential role of the MHC region in the susceptibility to Crohn's disease, even when no population associations or differing associations are identified.

Linkage analysis utilises families and thus is free from potential bias due to population stratification (inappropriate controls). However, the results of linkage analysis can be affected by other factors such as sample size (number of families), genetic heterogeneity (linked forms and unlinked forms within Crohn's disease), clinical heterogeneity (ulcerative colitis and Crohn's disease), and analytical approaches (parametric and nonparametric methods). Some cosegregation studies between Crohn's disease and HLA antigens in families with multiple members affected with Crohn's disease have shown evidence for linkage, ${ }^{14-17}$ while others did not. ${ }^{18-23}$ The reasons for such inconsistent results are unclear, but could be due to any combination of factors listed above. Genetic heterogeneity within Crohn's disease has been evidenced both by epidemiological observations, ${ }^{24}$ and genetic marker studies. ${ }^{561325}$ In an epidemiological study, ${ }^{24}$ we observed an increased empiric risk for IBD in relatives of Jewish probands compared with the relatives of Caucasian non-Jewish probands. Genetic marker studies have observed different associations not only between different populations (for example, DQB $1^{\star} 04$ association in a Japanese population, ${ }^{25}$ but $\mathrm{DQB} 1{ }^{\star} 0501$ in Caucasian populations from France $^{6}$ and North America ${ }^{5}$ ), but also within patients with Crohn's disease (for example, DRB $1^{\star} 03$ was negatively associated with fistulising Crohn's disease $\mathrm{e}^{13}$ ).

The use of non-parametric methods allows linkage to be evaluated without imposing any specific genetic model and without assuming related parameters, such as gene frequency and degree of penetrance. While sib pair methods are most often used for non-parametric linkage analysis, linkage analysis with other affected relative pairs can increase the statistical power to identify linkage. ${ }^{26}{ }^{27}$

Concurrence of ulcerative colitis and Crohn's disease in the same family exceeds the expected frequency by chance alone, suggesting these two disorders have some of their aetiology in common. ${ }^{24}$ However, the clinical differences between ulcerative colitis and Crohn's disease, and the differences observed in subclinical and genetic marker associations, strongly suggest that ulcerative colitis and Crohn's disease are also to a large extent genetically distinct. ${ }^{4}{ }^{28-30}$ Therefore, a clinically well defined homogeneous group of fami- lies with either ulcerative colitis or Crohn's disease will maximise the chance of identifying linkage between genetic markers and ulcerative colitis or Crohn's disease.

We therefore investigated evidence for or against the MHC linkage with Crohn's disease in a large number of US families with at least two sibs affected with Crohn's disease and/or other affected relative pairs, and with no known members affected with ulcerative colitis in the family (Crohn's disease only families). Both TNF microsatellite markers and HLA class I and class II data were used to generate haplotypes to determine identical by descent status in sib pairs and relative pairs. Nonparametric linkage methods were applied to these families and significant evidence for linkage between TNF-HLA haplotypes (the MHC region on short arm of chromosome 6) and Crohn's disease was found.

\section{Subjects and methods}

PATIENTS AND FAMILIES

The patients were ascertained through the IBD clinical programmes at Cedars-Sinai Medical Center, or referred by the Crohn's and Colitis Foundation of America and physicians nationwide. Through these patients, we recruited families with two or more sibs affected with Crohn's disease and with no known family history of ulcerative colitis. More distant relatives (than sibs) who were affected with Crohn's disease and connecting relatives were also included in this study. All family members were interviewed in person or by telephone to obtain detailed family and medical histories. Medical records were obtained to confirm the diagnosis. The study protocol was approved by the institutional review board of Cedars-Sinai Medical Center.

Blood samples were obtained from 323 individuals of 49 Crohn's disease only families. Among these families, 40 have two affected sibs, eight have three affected sibs, and one has four affected sibs. In addition, 15 of the 49 families have other distant affected relatives who were also included in this study. The sample population is composed of Caucasians from North America, 36\% being of Ashkenazi Jewish origin.

\section{DIAGNOSTIC CRITERIA FOR CD}

The diagnosis of Crohn's disease was based on conventionally accepted criteria as described previously. $^{31}$

\section{TNF GENOTYPING}

DNA isolation

High molecular weight DNA was isolated either from peripheral blood leucocytes (PBL) or Epstein-Barr virus transformed cell lines using the method previously described. ${ }^{32}{ }^{33}$

\section{TNF microsatellite typing}

TNF microsatellites were determined at five loci from genomic DNA from probands and relatives as previously described ${ }^{34}$ with modifications. ${ }^{11}$ The TNF genes are tandemly arranged within a 7 kilobase $(\mathrm{kb})$ region in the MHC, ${ }^{35} 250 \mathrm{~kb}$ centromeric to class I and 340 


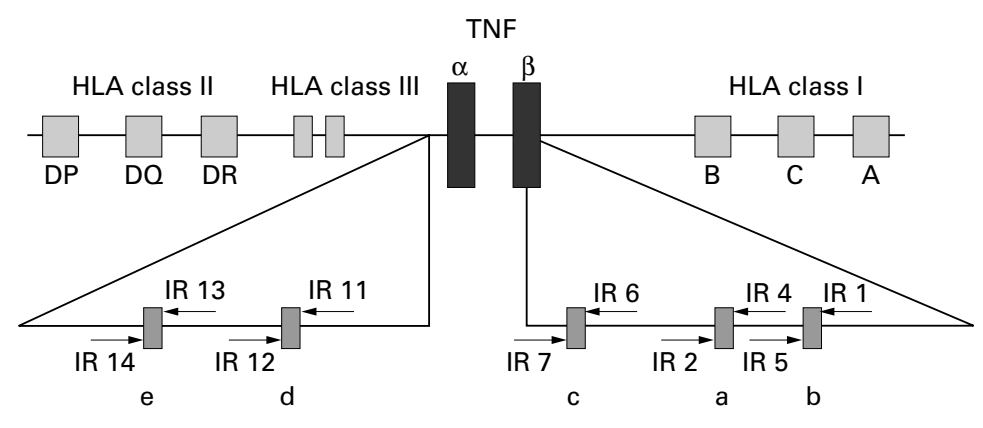

TNF microsatellites

Figure 1 Location and order of five TNF microsatellite loci within the HLA complex on chromosome 6. Arrows represent location and orientation of PCR primers used for typing. The exact orientation of TNFd and TNFe microsatellites with respect to the TNF locus has not been determined.

$\mathrm{kb}$ telomeric to class III on chromosome $6 .^{3637}$ The $\mathrm{TNFa}$ and $\mathrm{TNFb}$ microsatellites are located $3.5 \mathrm{~kb}$ upstream of the $\mathrm{TNFb}$ gene. $\mathrm{TNF}$ is located in the first intron of TNFb. The TNFd and TNFe microsatellite loci are located 8 to $10 \mathrm{~kb}$ downstream of the $\mathrm{TNFa}$ gene (fig 1). Polymerase chain reaction (PCR) products from at least one cell line of known TNF microsatellite haplotype ${ }^{34}$ per TNF microsatellite locus were analysed with the sample DNA to aid in interpretation of ambiguous alleles. Microsatellite alleles were interpreted separately by two investigators blinded to diagnosis. Successive alleles differ by one dinucleotide repeat for $\mathrm{TNFa}, \mathrm{TNF}, \mathrm{TNFd}$, and $\mathrm{TNFe}$. For $\mathrm{TNFb}$, alleles differ by one or two bases. ${ }^{34}$ The smallest allele is termed 1 , with larger alleles being numbered consecutively.

HLA SEROLOGICAL TYPING

Serological typing for all HLA antigens was performed using a two colour fluorochromasia, complement dependent, microcytotoxicity technique. ${ }^{38}$ Class I typing was performed directly on PBL or T cells. Class II typing was performed on B cells. T and/or B cells were obtained using Cell Prep I and/or II magnetic beads $^{39}$ (Dynal, Great Neck, New York, USA), respectively. All HLA-A, B, C, DR, and DQ serologically defined specificities with the exception of A43 (an antigen found only in South African Blacks) were tested for each typing. Sera were obtained by international exchange. The DR/DQ typings were supplemented by commercial trays (One Lambda, Canoga Park, California, USA).

TNF microsatellite polymorphisms and HLA class I and class II antigens were used to generate informative haplotypes so that identity by descent status could be determined, especially for distant affected relatives. Identity by descent refers to alleles that are the copies of the same ancestral allele. Both affected sibs and unaffected sibs were genotyped to increase the informativeness of the families when one or both parents were missing, and to be used for evaluation of discordant sib pairs. In four families with affected sib pairs, both parents were unavailable or non-informative in this region, and in 12 families, one parent was unavailable or non-informative. In the remaining 33 fami- lies, all four haplotypes were unequivocally determined.

LINKAGE AND STATISTICAL ANALYSIS

To increase the power of identifying linkage it is important to determine the frequency of the marker alleles or haplotypes shared by sib pairs or relative pairs identical by descent. Nonparametric linkage approaches were used to examine linkage between TNF-HLA haplotypes and Crohn's disease. Each of these methods, though based on the same principle, has its own utility, as delineated below. Given that this study used a candidate gene approach, which tested a specific hypothesis-whether the susceptibility to Crohn's disease is linked with the MHC haplotype-we used $\mathrm{p}<0.05$ as our criterion for evidence of linkage between this region and Crohn's disease susceptibility.

\section{Sib pair analysis with complete informative}

families

The observed numbers of affected sib pairs who share zero, one, and two haplotypes identical by descent are compared with expected numbers based on null hypothesis (no linkage), which are $25 \%, 50 \%$, and $25 \%$ respectively, by a $\chi^{2}$ goodness of fit test.

In this test, only sib pairs from complete informative families (both parents informative) were used. If a family has three affected sibs, it would contribute three sib pairs (sib 1-sib 2, sib 1-sib 3, and sib 2-sib 3); similarly, four affected sibs would provide six sib pairs. A total of 52 sib pairs were obtained from 25 families with two affected sibs, seven families with three affected sibs, and one family with four affected sibs. As the sib pairs from families with three or four affected sibs are not independent, we examined sib trios separately by comparing the observed frequencies of affected sib trios who all share zero, all share one, or all share two haplotypes identical by descent with the expected values. The expected values under the null (no linkage) hypothesis are $9 / 16,6 / 16$, and $1 / 16$, respectively.

\section{Allele sharing method with all informative haplotypes}

In order to utilise families with only one informative parent, we calculated the mean proportion of haplotypes $(\pi)$ shared identical by descent from the number of informative haplotypes (N) and the number that were identical by descent (I). Information was provided only by heterozygous parents with unambiguous parental transmission. When both parents were heterozygous and the parental origin of the haplotypes could be determined, each affected sib pair contributed two informative haplotypes (one from each parent). When one parent's genotype was missing, she/he did not contribute any information unless the genotype could be inferred by examining at least three children, including those affected and unaffected with Crohn's disease. This procedure does not require knowledge of marker allele frequencies in the population and uses all available information from parents. The estimated mean proportion 


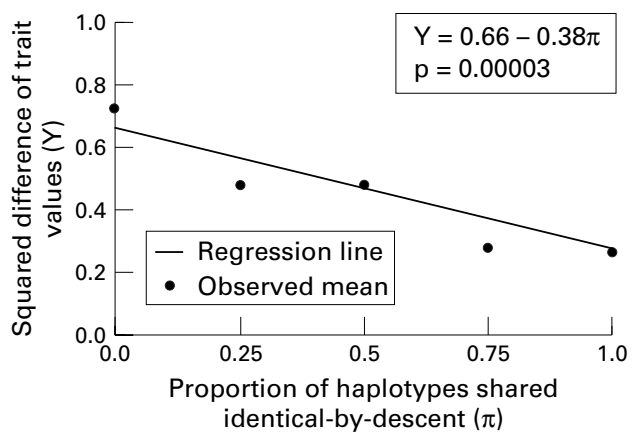

Figure 2 Significant linear relation between phenotypic concordance and proportion of shared TNF-HLA

haplotypes identical by descent among sibs. Those who share no haplotypes have the greatest degree of phenotypic discordance and those who share both are the most concordant. Thus, among sibs, similar genotypes (haplotype sharing) are correlated with similar phenotypes (both affected with Crohn's disease or both unaffected). These data are consistent with linkage between the MHC region and Crohn's disease.

of haplotypes shared identical by descent for a locus $(\pi=\mathrm{I} / \mathrm{N})$ was compared with 0.5 to test for linkage, using the statistic $\mathrm{Z}=2(\mathrm{I}-$ $\mathrm{N} / 2) / \mathrm{N}^{1 / 2}$ for an approximately standardised normal deviate. ${ }^{40}$ For this test, sib pairs from families with at least one informative parent (heterozygous) were used (118 informative haplotypes).

SIBPAL program in the SAGE package Two point linkage analysis was also performed using the SIBPAL program (version 2.7) of the Statistical Analysis for Genetic Epidemiology (SAGE) package. ${ }^{41}{ }^{42}$ This computerised sib pair analysis program estimates the proportion $(\pi)$ of alleles the sib pair shares identical by descent at that locus. The observed mean proportion of alleles shared by sib pairs was compared separately for concordant affected, concordant unaffected, and discordant sib pairs with expected 0.5 by $\mathrm{z}$ test (one sided). If the linkage between disease and locus exists, an increase of $\pi$ in both concordant affected and concordant unaffected groups, but a decrease of $\pi$ in the discordant group should be observed.

Although most sib pair methods focus on affected sib pairs, discordant sib pairs add additional information. If for some reason, not related to the disease under study, particular alleles tend to be transmitted from parents to offspring with a frequency greater than $50 \%$, there will be an increased proportion of allele sharing in all sib pairs. If only affected sib pairs are examined, this may falsely suggest that there was a linkage between disease susceptibility and the marker locus. To eliminate such false inference of linkage, we compared the mean proportion of sharing haplotypes in discordant sib pairs with that in affected concordant sib pairs. When there is linkage between the disease locus and the tested marker (the TNF-HLA region), marker allele sharing will be significantly greater when both sibs are clinically concordant than when they are discordant.

In this program, when the parents were not informative, an estimated proportion of allele sharing was used in the test. Therefore, in this analysis, all sib pairs were utilised, including affected concordant, discordant, and unaffected concordant sib pairs from fully informative and partially informative families.

Linear regression to test for possible linkage with SIBPAL in the SAGE package

Linear regression analysis with the SIBPAL program was also conducted to assess the prediction of the differences in disease status (Crohn's disease) according to the degree of sharing the TNF-HLA haplotype. In this method, all types of sib pairs are used and the affected individuals have a trait value 1 , the unaffected, 0 . The y axis is the squared difference between the pairs $(\mathrm{Y})$ and the $\mathrm{x}$ axis is the proportion of haplotypes shared identical by descent between the pairs $(\pi)$. For a qualitative trait, $\mathrm{Y}$ varies between 0 and 1 ( $\mathrm{Y}=0$ for $\mathrm{sib}$ pairs that have the same trait value - that is, both affected and unaffected, and $Y=1$ for sibs that have different trait values). The proportion of haplotypes shared identical by descent between the pairs $(\pi)$ ranges from 0 to 1 ( 0 for sharing none, 0.5 for sharing one, 1 for sharing two, and the values in between are derived from estimation by using non-informative parents).

If there were no linkage, a horizontal line would be observed - that is, the degree of clinical concordance would be independent of haplotype sharing. A significantly negative regression coefficient $b$ of the dependent variable (phenotype) $\mathrm{Y}$ on the independent variable (genotype) $\pi$ is taken as evidence for linkage (the more alleles are shared by a sib pair, the more alike their phenotypes are). This inverse relation is expressed by a negative regression line in this analysis (fig 2 ).

\section{Affected relative pair method}

The concept of the affected relative pair method is the same as that of the sib pair method; the only difference is the degree of relation. That is, in the affected relative pair method, one compares the observed frequency of affected relative pairs sharing alleles/ haplotypes identical by descent with the expected value if there was no linkage and the degree of the specific relations. ${ }^{26}{ }^{43}$ This method assesses whether a disease susceptibility gene has travelled through the pedigree to both affected individuals from their common ancestor together with the same marker allele. The advantage of using affected relative pairs is that the statistical power is greater with more distant relations between an affected pair given the same number of pairs analysed, and thus additional family members can be utilised, increasing the efficiency of individual pedigrees. The $\mathrm{z}$ statistic was used to compare the observed number of sharing, $\mathrm{Ti}$, with the expected number of sharing haplotypes identical by descent between relative pairs, $\mathrm{Pi}, \mathrm{z}=$ $(\Sigma \mathrm{Ti}-\Sigma \mathrm{Pi}-0.5) /[\Sigma \mathrm{Pi}(1-\mathrm{Pi})]^{1 / 2} .^{43}$

\section{Estimation of TNF-HLA contributions}

The increased risk over population prevalence to sibs due to a disease susceptibility gene in the MHC region was estimated using the 
Table 1 Haplotype sharing in concordant affected sibs with Crohn's disease

Affected sib pairs

Number of haplotypes shared

Observed number of sib pairs

Expected number of sib pairs

$\chi^{2}=8.769, \mathrm{df}=2, \mathrm{p}=0.013$ (for sharing zero, one, and two)

$\chi^{2}=8.308, \mathrm{df}=1, \mathrm{p}=0.004$ (for sharing zero $v$ sharing at least one)

Affected sib trios

Number of haplotypes shared by all three affected sibs

Observed number of sib trios

Expected number of sib trios

$\begin{array}{llll}0 & 1 & 2 & \text { Total } \\ 2 & 3 & 2 & 7 \\ 3.94 & 2.63 & 0.44 & 7\end{array}$

Table 2 Mean proportion of haplotypes shared in each type of sib pair ( $\pi$ )

\begin{tabular}{llllll}
\hline Type of sib pair & Number of sib pairs & Expected $\pi$ & Observed $\pi$ & SD & p Value \\
\hline Concordant normal & 64 & 0.5 & 0.58 & 0.35 & 0.031 \\
Discordant & 117 & 0.5 & 0.42 & 0.33 & 0.007 \\
Concordant affected & 70 & 0.5 & 0.60 & 0.29 & 0.002 \\
\hline
\end{tabular}

Table 3 Mean proportion of haplotypes shared in each type of sib pair $(\pi)$ for Fewish and non-fewish families separately

\begin{tabular}{lllllll}
\hline \multirow{2}{*}{ Ethnicity } & Type of sib pair & $\begin{array}{l}\text { Number of } \\
\text { sib pairs }\end{array}$ & Expected $\pi$ & Observed $\pi$ & SD & p Value \\
\hline Jewish & Concordant normal & 8 & 0.5 & 0.51 & 0.29 & 0.461 \\
& Discordant & 35 & 0.5 & 0.48 & 0.30 & 0.357 \\
\multirow{3}{*}{ Non-Jewish } & Concordant affected & 25 & 0.5 & 0.55 & 0.29 & 0.196 \\
& Concordant normal & 56 & 0.5 & 0.59 & 0.36 & 0.028 \\
& Discordant & 82 & 0.5 & 0.40 & 0.34 & 0.004 \\
& Concordant affected & 45 & 0.5 & 0.63 & 0.29 & 0.002 \\
\hline
\end{tabular}

equation from $\operatorname{Risch}^{44}: \lambda_{\text {MHC }}=\phi_{0} / \mathrm{p}$ (share 0 haplotype identical by descent given both are affected), where $\phi_{0}$ is the probability that two relatives share zero marker alleles or haplotypes identical by descent under the assumption of no linkage between the marker and the disease ( $\phi_{0}=0.25$ for sib pairs).

Under the multiplicative model, ${ }^{44}$ the proportion $\left(\mathrm{P}_{\mathrm{MHC}}\right)$ of total relative risk in siblings $\left(\lambda_{\mathrm{s}}\right)$ (or other relatives) contributed by the gene linked to the MHC region $\left(\lambda_{\mathrm{MHC}}\right)$ was determined by the following equation:

$$
\mathrm{P}_{\mathrm{MHC}}=\log \lambda_{\mathrm{MHC}} / \log \lambda_{\mathrm{s}} \times 100 \% .
$$

The lower bound of genetic contribution was estimated by a method derived by Rotter and Landaw. ${ }^{45}$ This method requires monozygotic (MZ) twin concordance data for Crohn's disease, the empiric sibling recurrence risks, and the sharing of identical by descent genes at the MHC by affected sib pairs as shown below:

\begin{tabular}{|c|c|c|c|c|}
\hline \multirow{2}{*}{$\begin{array}{l}\text { Coefficient } \\
\text { of genetic } \\
\text { contribution }\end{array}$} & \multirow{2}{*}{$=$} & $\begin{array}{l}\% \text { of affected } \\
\text { sib pairs identical } \\
\text { by descent }(=2)\end{array}$ & - & $\begin{array}{l}\% \text { of affected } \\
\text { sib pairs identical } \\
\text { by descent }(=0)\end{array}$ \\
\hline & & $\begin{array}{l}(25 \%) \times \mathrm{MZ} \\
\text { concordance/ } \\
\text { sibling risk }\end{array}$ & - & $\begin{array}{l}\% \text { of affected } \\
\text { sib pairs identical } \\
\text { by descent }(=0)\end{array}$ \\
\hline
\end{tabular}

\section{Results}

AFFECTED SIB PAIR ANALYSIS WITH COMPLETELY INFORMATIVE FAMILIES

Of 52 sib pairs affected with Crohn's disease, four shared no TNF-HLA haplotypes, 30 shared one, and 18 shared two. As shown in table 1, the observed frequency of sharing one or two haplotypes was significantly increased compared with the expected number under the no linkage assumption $(\mathrm{p}=0.013)$. After pool- ing the latter two groups (sharing one or two haplotypes), we observed 48 sib pairs sharing at least one haplotype which was significantly greater than the expected $39(\mathrm{p}=0.004)$.

Examining affected sib trios separately, we observed that in two out of seven informative families, both haplotypes were shared by all three sibs, in three families one haplotype was shared by all three sibs, and in two families, no haplotypes were shared by all three sibs (table 1). Although the number of sib trios was too small $(n=7)$ to perform statistical testing, the observed number of sharing among all three affected sibs seemed to be increased compared with the expected value. In the family with four affected sibs, one haplotype was shared by all four.

\section{ALLELE SHARING METHOD WITH INFORMATIVE} HAPLOTYPES

Of 118 informative haplotypes from 45 families, 72 haplotypes were shared by affected sib pairs. The observed haplotype sharing $(61 \%)$ was significantly greater than that expected $(50 \%)(p=0.008$ for the one sided test $)$.

SIB PAIR ANALYSIS WITH THE SIBPAL PROGRAM Both concordant affected sib pairs $(n=70)$ and concordant unaffected sib pairs $(n=64)$ had an increased mean proportion of sharing TNFHLA haplotypes compared with the expected 0.5 (0.60, $\mathrm{p}=0.002$; and 0.58, $\mathrm{p}=0.031$, respectively; table 2 ). In contrast, sharing in discordant sib pairs $(n=117)$ was significantly decreased (0.42) compared with expected (0.5) $(\mathrm{p}=0.007)($ table 2).

The difference between the two means in discordant sib pairs and in affected concordant sib pairs was highly significant $(p=0.0001$ for one sided test).

Jewish and non-Jewish families were also analysed separately with the SIBPAL program and the results are summarised in table 3 . It seems that the linkage effect of the HLA region is stronger in non-Jewish than it is in Jewish families, as indicated by the greater distortion from expected 0.5 in all sibling groups. Nevertheless, the allele sharing distortion in Jewish families is still apparent and consistent with linkage. It should be noted that the sample size in Jewish families is relatively small and that it is not surprising that the distortions in the Jewish group alone do not attain statistical significance. The observed proportion of allele sharing in affected sib pairs in Jewish families $(\pi=0.55)$ is smaller, but is not significantly different from that in non-Jewish families at this sample size $(\pi=0.63, p=0.3)$.

LINEAR REGRESSION ANALYSIS USING THE SIBPAL PROGRAM

Using all types of sib pairs we performed regression analysis with the trait difference between a sib pair as the dependent variable and the proportion of haplotype sharing between a sib pair as the independent variable. A highly significant negative regression line slope was observed $(-0.38, \mathrm{p}=0.00003$; fig 2$)$. In other words, those who shared zero haplotypes were the most often clinically 
Table 4 Observed and expected haplotype sharing between various affected relative pairs

\begin{tabular}{|c|c|c|c|c|c|}
\hline Relation & $\begin{array}{l}\text { Number of } \\
\text { pairs } N_{i}\end{array}$ & $P_{i}^{*}$ & $N_{i} P_{i}\left(1-P_{i}\right)$ & $\begin{array}{l}\text { Expected } \\
\text { number } N_{i} \\
P_{i}\end{array}$ & $\begin{array}{l}\text { Observed } \\
\text { number } T_{i}\end{array}$ \\
\hline Sibs & 52 & 0.7500 & 9.7500 & 39.00 & 48 \\
\hline Avuncular† & 9 & 0.5000 & 2.2500 & 4.50 & 6 \\
\hline 1 st cousin & 6 & 0.2500 & 1.1250 & 1.50 & 2 \\
\hline 1 st cousin once removed & 4 & 0.1250 & 0.4375 & 0.50 & 1 \\
\hline 2nd cousin & 7 & 0.0625 & 0.4102 & 0.44 & 1 \\
\hline Great uncle & 1 & 0.0625 & 0.0586 & 0.06 & 0 \\
\hline \multirow[t]{2}{*}{ Total } & 79 & & 14.0313 & 46.00 & 58 \\
\hline & $Z=3.07$ & $\mathrm{p}=0.001$ & & & \\
\hline
\end{tabular}

${ }^{\star}$ Expected probability of sharing a haplotype identical by descent.

tUncle/aunt-niece/nephew.
Crohn's disease only families, using a series of analytical methods, and maximising informativeness by combining both TNF microsatellite markers and HLA class I and class II serological markers. Using these approaches, we consistently observed linkage between Crohn's disease and the TNF-HLA region of MHC with all methods of analysis. It seems that the HLA linkage effect is stronger in non-Jewish families than it is in Jewish families, but is observed in both groups.

In our population, we have identified both association and linkage between the HLA region genes and Crohn's disease. Our previous case control studies (unrelated patients with Crohn's disease and controls) showed an association of HLA class II genes (DR1/DQ5) and a TNF haplotype (a2b1c2d4e1) with Crohn's disease. ${ }^{511}$ Fourteen of 49 families in the current study have the Crohn's disease associated TNF haplotype and only in two of these families was this haplotype shared by the affected sibs. Although the number is too small to provide any conclusive results about the association, these data do suggest that the observed TNF or HLA class II gene associations are due to linkage disequilibrium between these genes and putative Crohn's disease susceptibility genes located close to the MHC region. In other words, the tested TNF haplotypes and DR1/DQ5 themselves are probably not the disease causing gene(s). There could be more specific variations in the TNF or class II loci; or a combination of alleles at different loci which provide susceptibility. This concept of a disease predisposing haplotype has been observed in other HLA linked diseases such as insulin dependent diabetes mellitus. ${ }^{47}$

For this study, we included Crohn's disease only families in order to reduce disease heterogeneity and increase the power for identifying linkage. In these Crohn's disease only families, we observed excessive sharing of TNF-HLA haplotypes in concordant affected and concordant unaffected pairs, as well as reduced sharing in discordant pairs. This pattern provides strong evidence for linkage. As Crohn's disease has variable age of onset, some clinically normal sibs may have the disease susceptibility gene and develop the disease later in time. Therefore, unaffected sib pairs may contain some future discordant sib pairs and discordant sib pairs may contain some future concordant affected sib pairs. Distant affected relatives, who are unlikely to share household environmental factors, also provided further supportive evidence for linkage.

In our study population, it seems that both ulcerative colitis (data not shown) and Crohn's disease show the same trends of cosegregation with HLA haplotypes. Although we do not have enough ulcerative colitis families to firmly substantiate the linkage between the HLA and ulcerative colitis at this time, a recent genome scan study from England ${ }^{48}$ observed a tentative linkage between a marker, D6S276, lying close to the MHC complex, and ulcerative colitis.

Although the evidence for linkage is clear in our Crohn's disease multiplex families, it is quite possible that some populations may not

\section{Discussion}

In this study, we critically examined the hypothesis of linkage between Crohn's disease and the MHC region on the short arm of chromosome 6 . We did so by limiting our analysis to 
exhibit the same effect of the MHC region. This can be due to genetic aetiological heterogeneity. That is, it is increasingly apparent that several different genes and mechanisms can cause an individual to develop Crohn's disease. It has been shown in animal models that knock outs of the $\mathrm{T}$ cell receptor gene, the interleukin 2 (IL-2) gene, or the IL-10 gene, can all lead to clinical colitis in mice. ${ }^{49-51}$ Thus, the effects of certain genes may be more predominant in one population than in another population. The genome scan results in Crohn's disease seem to support this hypothesis as a chromosome 16 gene (IBD1) is important in French ${ }^{29}$ and US populations ${ }^{30} 52$ but not as important in the English population. ${ }^{48}$ In contrast, chromosome 3, 7, and 12 markers show significant linkage in the English population but were not identified in the French population. Furthermore, IBD1 is linked with Crohn's disease only in non-Jewish Caucasian families, but not in Jewish families ${ }^{30}$ drawn from the same geographic areas. Though such data are not available at this time, detailed clinical characterisation of affected patients from the linked families versus unlinked families might provide some insight on aspects regarding potential genetic heterogeneity.

Given certain assumptions, the gene(s) linked to the MHC region in these data was estimated to contribute at most $29-33 \%$ of the total increased risk in sibs over the population risk of Crohn's disease. Applying the method of Rotter and Landaw ${ }^{45}$ with monozygotic twin concordance data from Sweden, ${ }^{2}$ we obtained a lower bound for the estimate of the MHC contribution $(10 \%)$. This potential range of genetic contribution could account, at least in part, for the difficulty of observing linkage in every study. Furthermore, even in our population, other genes, some of which may contribute an even greater risk to Crohn's disease, remain to be identified. The power of identifying such genes may be augmented by detailed studies of the phenotype, both at the clinical and subclinical level.

The authors wish to thank patients, their families, and referring physicians for their support of our ongoing genetic studies of inflammatory bowel disease. This work was supported by the National Institutes of Health grant DK46763, a grant from the Crohn's and Colitis Foundation of America (SEP, SRT), and the Cedars-Sinai Board of Governors' Chair in Medical Genetics (JIR). Some of the results in this paper were obtained by using the program package SAGE, which is supported by a US Public Health Service Resource Grant (1P41RR03655) from the National Center for Research Resources.

1 Yang H, Rotter JI. Genetic aspects of idiopathic inflammatory bowel disease. In: Kirsner JB, Shorter RG, eds. Inflammatory bowel disease. Baltimore: Williams and Wilkins, 1995:301-31.

2 Tysk C, Lindberg E, Jarnerot G, et al. Ulcerative colitis and Crohn's disease in an unselected population of monozygotic and dizygotic twins: a study of heritability and the influence of smoking. Gut 1988;29:990-6.

3 Fujita K, Naito S, Okabe N, et al. Immunological studies in Crohn's disease. I. Association with HLA systems in Japanese. F Clin Lab Immunol 1984;14:99-102.

4 Kobayashi K, Atoh M, Yagita A, et al. Crohn's disease in the Japanese is associated with the HLA-DRw53. Exp Clin Immunogenet 1990;7:101-8.

5 Toyoda H, Wang S-J, Yang H, et al. Distinct association of HLA class II gene with inflammatory bowel disease.
Gastroenterology 1993;104:741-8.

6 Danze PM, Colombel JF, Jacquot S, et al. Association of HLA class II genes with susceptibility to Crohn's disease. Gut 1996;39:69-72.
7 Forcione DG, Sands B, Isselbacher KJ, et al. An increased risk of Crohn's disease in individuals who inherit the HLA class II DRB3*0301 allele. Proc Natl Acad Sci USA 1996;93:5094-8.

8 Reinshagen M, Loeliger C, Kuehnl P, et al. HLA class II gene frequencies in Crohn's disease: a population based analysis in Germany. Gut 1996;38:538-42.

9 van Dullemen HM, van Deventer SJ, Hommes DW, et al. Treatment of Crohn's disease with anti-tumor necrosis factor chimeric monoclonal antibody (cA2). Gastroenterology 1995;109:129-35.

10 Targan SR, Hanauer SB, van Deventer SJH, et al. A short-term study of anti-tumor necrosis factor-alpha chimeric monoclonal antibody (cA2) in Crohn's disease. $N$ Engl f Med 1997;337:1029-35.

11 Plevy SE, Targan SR, Yang H, et al. Tumor necrosis factor microsatellites define a Crohn's disease associated haplotype on chromosome 6. Gastroenterology 1996;110:105360 .

12 Louis E, Satsangi J, Roussomoustakaki M, et al. Cytokine gene polymorphisms in inflammatory bowel disease. Gut 1996:39:705-10.

13 Bouma G, Poen A, Garcia-Gonzalez MA, et al. HLADRB ${ }^{\star} 03$, but not the TNFA-308 promoter gene polymorphism, confers protection against fistulising Crohn's disease. Immunogenetics 1998;47:451-5.

14 Schwartz SE, Siegelbaum SP, Fazio TL, et al. Regional enteritis evidence for genetic transmission by HLA typing. Ann Intern Med 1980;93:424-7.

15 Achord JF, Gunn GH, Jackson JF. Regional enteritis and HLA concordance in multiple siblings. Am f Hum Genet 1982;27:330-2.

16 Purrmann J, Miller B, Lapsien B, et al. HLA haplotype study in familial Crohn disease. Zeitschrift fur Gastroenterologie 1985;23:432-7.

17 Kuhnl P, Sibrowski W, Bohm BO, et al. HLA antigen frequencies in familial Crohn's disease (CD). Beitr frequencies in familial C
Infusionsther 1990;26:284-6.

18 Pena AS, Biemond I, Weterman IT, et al. HLA antigen distribution and HLA haplotype segregation in Crohn's disease. Tissue Antigens 1980;16:56-61.

19 Eade OE, Moulton C, MacPherson BR, et al. Discordant HLA haplotype segregation in familial Crohn's disease. Gastroenterology 1980;79:271-5.

20 Colombel JF, Guillemot F, Gossum AV, et al. Familial Crohn's disease in multiple siblings: no linkage to the HLA system. Gastroenterol Clin 1989;13:676-8.

21 Hugot J-P, Laurent-Puig P, Gower-Rousseau C, et al. Linkage analyses of chromosome 6 loci, including HLA, in familial aggregations of Crohn disease. Am f Med Genet 1994;51:1-8.

22 Naom I, Lee J, Ford D, et al. Analysis of the contribution of HLA genes to genetic predisposition in inflammatory HLA genes to genetic predisposition in infla
bowel disease. Am ₹ Hum Genet 1996;59:226-33.

23 Satsangi J, Welsh KI, Bunce M, et al. Contribution of genes of the major histocompatibility complex to susceptibility and disease phenotype in inflammatory bowel disease. Lancet 1996;347:1212-17.

24 Yang $\mathrm{H}$, McElree C, Roth M-P, et al. Familial empiric risks for inflammatory bowel disease: differences between Jews and non-Jews. Gut 1993;34:517-24.

25 Nakajima A, Matsuhashi N, Kodama T, et al. HLA-linked susceptibility and resistance genes in Crohn's disease. Gastroenterology 1995;109:1462-7.

26 Risch N. Linkage strategies for genetically complex traits. III. The effect of marker polymorphism on analysis of affected relative pairs. Am f Hum Genet 1990;46:229-41.

27 Bishop DT, Williamson JA. The power of identity-by-state methods for linkage analysis. Am f Hum Genet 1990;46: $242-65$

28 Yang H, Rotter JI. The genetics of inflammatory bowel disease. In: Targan SR, Shanahan F, eds. Inflammatory bowel disease: from bench to bedside. Baltimore: Williams and Wilkins, 1994:32-64.

29 Hugot J-P, Laurent-Puig P, Gower-Rousseau C, et al. Mapping of a susceptibility locus for Crohn's disease on chromosome 16 by a genome-wide nonparametric linkage analysis. Nature 1996;379:821-3.

30 Ohmen JD, Yang H, Yamamoto KK, et al. Susceptibility locus for inflammatory bowel disease on chromosome 16 has a role in Crohn's disease, but not in ulcerative colitis. Hum Mol Genet 1996;5:1679-83.

31 Vasiliauskas EV, Plevy SE, Landers CJ, et al. Perinuclear antineutrophil cytoplasmic antibodies (pANCA) in patients with Crohn's disease define a clinical subgroup. Gastroenterology 1996;110:1810-19.

32 Yang $\mathrm{H}$, Rotter JI, Toyoda $\mathrm{H}$, et al. Ulcerative colitis: a genetically heterogeneous disorder defined by genetic (HLA class II) and subclinical (anti-neutrophil cytoplasmic antibodies) markers. $\mathcal{F}$ Clin Invest 1993;92:1080-4.

33 Redford A, Magalong D, Onohara-Toyoda M, et al. Restriction fragment length polymorphism (RFLP) heterogeneity of HLA-DQ beta gene associated with DNA fragment identical to the DR1-beta gene DNA structure. Dis Markers 1991;9:257-63.

34 Udalova IA, Nedospasov SA, Webb GC, et al. Highly informative typing of the human TNF locus using six adjacent polymorphic markers. Genomics 1993;16:180-6.

35 Spies T, Morton CC, Nedospasov SA, et al. Genes for the tumor necrosis factors a and $\mathrm{b}$ are linked to the human major histocompatibility complex. Proc Natl Acad Sci USA 1986;83:8699-702.

36 Carroll MC, Katzman P, Alicot EM, et al. Linkage map of the human major histocompatibility complex including the 
tumor necrosis factor genes. Proc Natl Acad Sci USA 1987; 84:8535-9.

37 Dunham I, Sargent CA, Trowsdale J, et al. Molecular mapping of the human major histocompatibility complex by pulse-field gel electrophoresis. Proc Natl Acad Sci USA 1987;84:7237-4

38 Lizak GE, Grumet FC. A new micromethod for the in vitro detection of antiplatelet antibodies: C-FDA thrombocytotoxicity. Hum Immunol 1980;1:87-96.

39 Tyan DB, Li VA, Czer L, et al. Intravenous immunoglobulin suppression of HLA alloantibody in highly sensitized transplant candidates and transplantation with a histoincompatible organ. Transplantation 1994;57:553-62.

40 Hashimoto L, Habita C, Beressi JP, et al. Genetic mapping of a susceptibility locus for insulin-dependent diabetes mellitus on chromosome 11q. Nature 1994;371:161-4.

41 SAGE. Statistical Analysis for Genetic Epidemiology, Release 3.0. Computer program available from the Department of Epidemiology and Biostatistics, Rammelkamp Center for Education and Research, MetroHealth Campus. 3rd edn. Cleveland: Case Western Reserve University, 1997.

42 Tran LD, Elston RC, Keats BJB, et al. Sib pair linkage program (SIBPAL) user's guide. Part of the SAGE Release 3.0 documentation, Department of Epidemiology and Biostatistics, Case Western Reserve University, 1997.

43 Cantor RM, Rotter JI. Marker concordance in pairs of distant relatives: a new method to detect genetic heterogeneity. Clin Res 1988;36:A184
44 Risch N. Assessing the role of HLA-linked and unlinked determinants of disease. Am f Hum Genet 1987;40:1-14.

45 Rotter JI, Landaw EM. Measuring the genetic contribution of a single locus to a multilocus disease. Clin Genet 1984;26:529-42.

46 Calkins BM, Mendeloff AI. The epidemiology of idiopathic inflammatory bowel diease. In: Kirsner JB, Shorter RG, eds. Inflammatory bowel disease. Baltimore: Williams and Wilkins, 1995:31-68.

47 Erlich H, Zeidler A, Chang J, et al. HLA class II alleles and susceptibility and resistance to insulin dependent diabetes mellitus in Mexican-American families. Nature Genetics mellitus in Mexic

48 Satsangi J, Parkes M, Louis E, et al. Two stage genome-wide search in inflammatory bowel disease provides evidence for susceptibility loci on chromosomes 3,7 and 12. Nature Genetics 1996;14:199-202.

49 Sadlack B, Merz H, Schorle H, et al. Ulcerative colitis like disease in mice with a disrupted interleukin-2 gene. Cell 1993;75:253-61.

50 Kuhn R, Lohler J, Rennick D, et al. Interleukin-10-deficient mice develop chronic enterocolitis. Cell 1993;75:263-74.

51 Mombaerts P, Mizoguchi E, Grusby MJ, et al. Spontaneous development of inflammatory bowel disease in $\mathrm{T}$ cell development of inflammatory bowel dise

52 Cho JH, Fu Y, Kirschner BS, et al. Confirmation of a susceptibility locus for Crohn's disease on chromosome 16. Inflammatory Bowel Disease 1997;3:186-90. 


\section{LETTERS TO THE EDITOR}

Angina pectoris and oesophageal angina

EDIToR,- - I enjoyed the prospective study by Cooke et al (Gut 1998;42:323-329) on the relation between oesophageal abnormalities and chest pain in patients with normal coronary angiograms and with angina pectoris. This study confirms the findings of previous studies ${ }^{12}$ that the oesophagus is responsible for chest pain in a high percentage of patients with coronary artery disease, and that an episode of gastrooesophageal reflux nearly always triggers this pain.

However, no explanation for this unexpected finding has been given. The tentative proposition that it is the result of a decreased angina threshold ${ }^{3}$ and a reflex coronary ischaemia, both induced by the contact of acid with the oesophageal mucosa, is not acceptable for two reasons: firstly, because this oesophagocardiac reflex may be the basis for linked angina but not for oesophageal angina and, secondly, because the patients should have shown simultaneous electrocardiographic (ECG) abnormalities during the pain induced by the acid perfusion test Unfortunately, a concurrent ECG was not performed during $\mathrm{pH}$ monitoring. This intriguing finding gives rise to two questions: why do these patients have such a high incidence of gastro-oesophageal reflux and why does this so frequently cause them pain?

I believe that the first question can be answered by the fact that patients with angina pectoris are usually prescribed long term medication such as nifedipine or nitroderivatives; these drugs are potent inhibitors of lower oesophageal sphincter tone, which is the main antireflux barrier. It would be interesting to know whether the patients with angina from Cooke and colleagues' study had taken this type of medication for long periods, and whether their lower oesophageal sphincter tone was below normal at the time of the study. In a previous study, we measured manometrically the lower oesophageal sphincter tone in patients with angina after a drug washout, and found a significantly lower value than normal. ${ }^{5}$ It seems probable that the chronic consumption of spasmolytic drugs may have reduced this tone, giving patients with coronary artery disease the appearance of pathological gastrooesophageal reflux. Furthermore, it is possible that the absence of oesophageal spastic disorders, such as nutcracker oesophagus, could be attributed to the long term pharmacological suppression of oesophageal contractile activity.

With regard to the second question, it is very odd that patients with angina and gastro-oesophageal reflux complain mainly of retrosternal pain instead of the more common symptoms of gastro-oesophageal reflux - for example, heartburn, acid regurgitation, etc. ${ }^{6}$ Previous studies have shown that there is a decrease in the pain perception threshold of patients with oesophageal angina and normal coronary angiograms, but we do not know whether pain perception in patients with oesophageal angina and coronary artery disease is similarly altered. I would expect a positive result from research on this matter, because it is not unreasonable to suppose that chronic cardiac pain may have sensitised the nociceptive neurones of the dorsal horn of the spinal cord, ${ }^{8}$ where the nociceptive fibres coming from the oesophageal mucosa also converge, thus developing a secondary hyperalgesia allodynia. ${ }^{9}$ Should spinal hyperalgesia be present, episodes of gastrooesophageal reflux that are generally not perceived to cause pain, could simulate the pain of angina.

M BORTOLOTTI

Department of Internal Medicine and Gastroenterology, University of Bologna, Via Massarenti 48, 40138 Bologna, Italy

1 Bortolotti M, Marzocchi A, Bacchelli S, et al. The esophagus as a possible cause of chest pain in patients with and without angina pectoris. Hepatogastroenterology 1990;37:316-18.

2 Lux G, Van Els J, The GS, et al. Ambulatory oesophageal pressure, $\mathrm{pH}$ and ECG recording in patients with normal and pathochest pain. Neurogastroenterol Motil 1995;7:2330 .

3 Davies AH, Page Z, Rush EM. Oesophageal stimulation lowers external angina threshold. Lancet 1985; ;i: 1011

4 Chauhan A, Patch MC, Schoffield PM. Effect of oesophageal acid instillation on coronary blood flow. Lancet 1993;341:1309-10.

5 Bortolotti M, Labriola E, Bacchelli S, et al. "Oesophageal angina" in patients with angina pectoris: a possible side effect of chronic therapy with nitroderivatives and $\mathrm{Ca}$ antagonists. Ital f Gastroenterol 1992;24:405-8.

6 De Meester TR, Johnson LF, Joseph GJ, et al. Patterns of gastroesophageal reflux in health and disease. Ann Surg 1976;184:459-70.

7 Richter JE, Bansh CF, Castell DO. Abnormal sensory perception in patients with esophageal chest pain. Gastroenterology 1986;91:845-52.

8 Mayer EA, Gebhart GF. Basic and clinical Mayer EA, Gebhart GF. Basic and clinical aspects of visceral hyp
ogy 1994;107:271-93.

9 Cervero F. Visceral pain: mechanisms of peripheral and central sensitization. Ann Med 1995; 27:235-9.

\section{Intrahepatic HCV levels in chronic HCV infection}

Editor,-Haydon et al (Gut 1998;42:570-5) have found that hepatitis $\mathrm{C}$ virus (HCV) RNA is present in the liver of $87 \%$ of unselected patients with circulating antiHCV antibody (confirmed by recombinant immunoblot assay) and negative serum HCV RNA by polymerase chain reaction (PCR). Furthermore, $70 \%$ of these patients had normal serum alanine aminotransferase (ALT) concentrations. Previous experience from both our group and others would suggest that most of these patients would be HCV RNA negative in liver tissue, whether treated or untreated..$^{1-3}$ In fact, Fong and colleagues have shown that eight patients with anti-HCV antibody, persistently normal ALT concentrations (mean 14.5 months), and negative serum HCV RNA, had no HCV RNA detectable in liver or peripheral lymphocytes using qualitative reverse transcriptase (RT) PCR. ${ }^{2}$ Recently, we used a multi-cycle RT PCR (SuperQuant, National Genetics Institute, Culver City, CA, USA) to quantify HCV RNA in both liver and serum. Ten untreated patients with detectable anti$\mathrm{HCV}$ antibody (including one patient who was coinfected with HIV) were negative in serum using the SuperQuant assay: eight of these patients had raised ALT concentrations, and all had a liver biopsy sample taken.
Liver tissue samples were assayed for HCV RNA and nine patients were negative in liver tissue. Three additional patients had negative serum for HCV RNA (Roche Amplicor, Roche Molecular Systems) and had no detectable liver HCV RNA (SuperQuant). However, using the SuperQuant assay, small amounts of HCV RNA (all less than three logs) were found in their serum. We speculate that this more sensitive assay might have amplified extrahepatic viral sequences. ${ }^{4}$

Based on our data, we believe that most patients with negative HCV RNA in serum will be found to be HCV RNA negative in liver, particularly when ALT concentrations are normal. Furthermore, very sensitive assays may detect small quantities of HCV RNA (which may be extrahepatic in origin) in serum but not in liver.

M BONACINI A G REDEKER USC School of Medicine Liver Unit, Downey, California, USA

Marcellin P, Boyer N, Gervais A, et al. Long term histologic improvement and loss of detectable intrahepatic HCV RNA in patients with chronic hepatitis $\mathrm{C}$ and sustained response to interferon alpha therapy. Ann Intern Med 1997:127:875-81.

2 Fong TL, Briggs WK, Valinluck B, et al. Do patients with normal ALT and anti HCV reactivity have occult infection [abstract]? Hepatology 1994:20:348A.

3 Lau TYD, Kleiner DE, Ghany MG, et al. 10 year follow up after interferon- $\alpha$ therapy for chronic hepatitis C. Hepatology 1998:28:11217.

4 Laskus T, Radkowski M, Wang LF, et al. The presence of active hepatitis $\mathrm{C}$ virus replication in lymphoid tissue and various organs in patients coinfected with human immunodeficiency virus type 1 [abstract]. Hepatology 1998:28:276A.

\section{Reply}

Editor,-We thank Drs Bonacini and Redeker for their interesting comments and data. Their study, which used a multi-cycle RT PCR assay with a detection sensitivity of 100 copies HCV RNA/ml serum, showed that only one patient out of 10 with detectable anti-HCV antibody was positive in liver tissue, when concurrently negative in serum.

Using a limiting dilution assay (which has already been proved to have significant reproducibility when multiple samples are tested in duplicate, and a significant correlation with three commercial assays ${ }^{1}$ ) with a detection sensitivity of $80 \mathrm{HCV}$ copies $/ \mathrm{ml}$ of serum (in a $5 \mathrm{ml}$ sample of serum), we showed that 10 out of 12 patients who were RT PCR negative in serum, were RT PCR positive in liver. Significantly, all 12 patients had ongoing inflammation, diagnosed by diagnostic laparoscopy and from liver biopsy samples.

We would be interested to know the histological findings taken from the liver biopsy samples in Dr Bonacini's study; ongoing hepatic inflammation indicates the continued presence of the virus in very small quantities. We maintain our hypothesis that such patients are viraemic below the detection sensitivity level of the above assays (which is similar, although the assays have not been compared), and that it is impossible to be certain that the infection has been cleared completely even at a detection sensitivity of 100 copies $\mathrm{HCV} / \mathrm{ml}$.

However, the prognostic importance of these data is that serum RT PCR negative 
patients, with chronic $\mathrm{HCV}$ infection, need to be followed up for an indefinite period because there is no indication that they are immune from progressive liver disease in the future.

G H HAYDON

Department of Medicine,

Royal Infirmary of Edinburgh,

Edinburgh, UK

1 Hawkins A, Davidson F, Simmonds P. Comparison of plasma loads among individuals infected with hepatitis C virus genotypes 1,2 and 3 by with hepatitis C virus genotypes 1,2 and 3 by quantiplex HCV Monitor assay, and an in-house limiting dilution method. f Clin Microbiol 1997;35:18792 .

\section{Is exposure to a patient with Crohn's disease an environmental factor for developing the disease?}

EDIToR,-A recent study of intestinal permeability in patients with Crohn's disease, their spouses, and first degree relatives, has concluded that baseline permeability is influenced by environmental factors, whereas permeability provoked by acetylsalicylic acid is genetically determined (Gut 1999;44:96100). The significance of increased intestinal permeability is still unclear, but animal models show that it may be an early event in the inflammatory process, suggesting that environmental and hereditary factors interact in the pathogenesis of Crohn's disease.

This study also observed that baseline permeability in relatives who were not living with the patient with Crohn's disease at the time of diagnosis, or at the time of the permeability test, was considerably less abnormal than that of relatives who lived with the patient. Similarly, a subcategory of spouses who had lived with their Crohn's disease partners since before diagnosis, had a higher percentage of increased permeability than other spouses.

Previously, increased occurrence of Crohn's disease in a patient's relatives has been assumed to be indicative of genetic predisposition, and has not been linked to frequency of contact. A study of clusters of cases from the same family suggested that, based on a temporal succession of presentations, an infectious microorganism might be involved. ${ }^{1}$ Several studies have proposed that spouses of patients with Crohn's disease show a higher frequency of the disease than expected ${ }^{2-4} ;$ however, these studies were based on estimates of disease prevalence and could be influenced by under-reporting of such cases. Clusters of unrelated patients with Crohn's disease who shared a close relationship or lived in the same community before developing the disease have also been reported. ${ }^{56}$

Finally, a study of disease transmission in animal models also indicated that Crohn's disease may have an infectious aetiology. It showed consistently that animals inoculated with isolates from patients with Crohn's disease developed chronic intestinal inflammation, whereas animals inoculated with isolates from patients with ulcerative colitis or other gastrointestinal diseases did not $^{7}$; this inflammation could be prevented by addition of an antibiotic (ampicillin) to the inoculate. $^{8}$

The establishment of a positive correlation between intestinal permeability in spouses and relatives and the length of association and frequency of contact with patients with Crohn's disease could resolve whether devel- opment of the disease is due to this environmental factor. Thus, it may be useful to perform an observational study which compares the frequency, length, and nature of contact between all first degree relatives and the patient with Crohn's disease. Soderholm et $a l$ 's study of intestinal permeability included only 34 of 123 first degree relatives of 39 patients with Crohn's disease, because many relatives had little social contact with the patients. It is only through an exhaustive search for all relatives that frequency of contact between patients with Crohn's disease and relatives who have the same genetic predisposition towards the disease can be linked to the risk of developing the disease. Such a study may also resolve whether earlier onset of the disease in familial cases, compared with time of onset in people who develop Crohn's disease independently, is caused by genetic anticipation or environmental factors.

M ALIC 1754 S Grant \#4 San Mateo, CA 94402, USA

1 Van Kruiningen HJ, Colombel JF, Cartun RW, et al. An in-depth study of Crohn's disease in two French families. Gastroenterology 1993;104:351-60.

2 Lobo AJ, Foster PN, Sobala GM, et al. Crohn's disease in married couples [letter]. Lancet 1988;i:704-5.

3 Bennett RA, Rubin PH, Present DH, et al. Frequency of inflammatory bowel disease in offspring of couples both presenting with inflammatory bowel disease. Gastroenterology 1991;100:1638-43.

4 Comes MC, Gower Rousseau C, Colombel JF et al. Inflammatory bowel disease in married couples: 10 cases in Nord Pas De Calais region of France and Liege county of Belgium. Gut 1994;35:1316-18.

5 Allan RN, Pease P, Ibbotson JP. Clustering of Crohn's disease in a Cotswold village. $Q \mathcal{F} \mathrm{Med}$ 1986;59:473-8.

6 Aisenberg J, Janowitz HD. Cluster of inflammaAisenberg J, Janowitz $\mathrm{HD}$. Cluster of inflamma-
tory bowel disease in three close college tory bowel disease in three close college
friends? $\mathcal{F}$ Clin Gastroenterol 1993;17:18-20.

7 Simonowitz D, Block GE, Riddell RH, et al. Simonowitz D, Block GE, Riddell RH, et al.
Inflammatory tissue reaction in rabbit bowel injected with Crohn's homogenates. Am f Surg 1979;138:415-17.

8 Donnelly BJ, Delaney PV, Healy TM. Evidence for a transmissible factor in Crohn's disease. Gut 1977;18:360-3.

\section{Reply}

EdIToR,-We thank Dr Alic for his interesting comments on our study of intestinal permeability in relatives and spouses of patients with Crohn's disease. We agree that Crohn's disease may be part of an infectious process, and our study does not contradict this hypothesis. One of our conclusions was that baseline permeability may be a function of unknown environmental factors that could be directly related to contact with, or factors shared with, the patients with Crohn's disease-for example, an infectious agent or dietary factors.

As Dr Alic suggests, we have further analysed the relation between length of exposure of the spouses and relatives to the patients with Crohn's disease and baseline permeability in these people (table 1). We found that all spouses with an increased baseline permeability (above the 95th percentile of controls) had lived with their Crohn's disease partner for more than 10 years. However, a study of the relatives showed that there was no link between length of time living with the patient and baseline permeability. Neither group showed any correlation between permeability after ingestion of acetylsalicylic acid and time of exposure to patients.
Table 1 Number of spouses with high and low baseline intestinal permeability in relation to duration of cohabitation with patients with Crohn's disease

\begin{tabular}{lclc}
\hline & $\begin{array}{c}\text { Normal } \\
\text { L:M }\end{array}$ & $\begin{array}{l}\text { High } \\
\text { L:M }\end{array}$ & Total \\
\hline Less than 10 years & 9 & 0 & 9 \\
More than 10 years & 8 & $5^{\star}$ & 13 \\
Total & 17 & 5 & 22
\end{tabular}

Permeability is expressed as the lactulose:mannitol ratio (L:M). ${ }^{\star}$ Increased number compared with less than 10 years; $p=0.054$; Fisher's exact test.

We also agree that a search for all the relatives of all of our patients with Crohn's disease would provide more information. A group from Belgium has performed a thorough study of all relatives of a group of such patients ${ }^{1}$; they showed increased baseline permeability in subgroups of both first degree relatives and spouses, and suggested a common environmental factor as the cause. In conclusion, we cannot exclude a transmissible factor as the cause of increased baseline permeability, although it is not known whether this accounts for permeability provoked by acetylsalicylic acid, although our data do not indicate an environmental cause.

Does the increase in baseline, and/or provoked, permeability predispose the spouse or relative towards developing Crohn's disease? This is a different and more difficult issue to tackle. It has yet to be established whether a sustained increase in intestinal permeability can trigger inflammation, but circumstantial evidence is in favour of this as a possible mechanism. Knockout mice which are deficient in N-cadherin (an adhesion molecule important for epithelial structure) develop intestinal inflammation that resembles Crohn's disease. ${ }^{2}$ Moreover, we have found that inflammation in recurrent Crohn's ileitis is preceded by increased epithelial permeability to proteins. ${ }^{3}$ However, further studies are needed to explain the pathogenic importance of increased epithelial permeability to the development of mucosal inflammation in Crohn's disease.

In the past 10 years, several studies have shown subgroups of relatives with increased baseline permeability, ${ }^{4-8}$ and four studies have shown increased mucosal reactivity to nonsteroidal anti-inflammatory drugs in first degree relatives. ${ }^{9-12}$ A multicentre follow up study of the relatives included in these studies could discover whether relatives with increased baseline and/or stimulated permeability will eventually contract disease.

\section{J D SODERHOLM G OLAISON R SJODAHL \\ Department of Surgery, University Hospital, S-581 85 Linkoping, Sweden}

1 Peeters M, Geypens B, Claus D, et al. Clustering of increased small intestinal permeability in families with Crohn's disease. Gastroenterology 1997;113:802-7.

2 Hermiston ML, Gordon JI. Inflammatory bowel disease and adenomas in mice expressing a dominant negative N-Cadherin. Science 1995; 270:1203-7.

3 Söderholm JD, Holmgren Peterson K, Olaison $\mathrm{G}$, et al. Epithelial permeability to proteins in the non-inflamed ileum of Crohn's disease. Gastroenterology 1999;117:65-72.

4 Ainsworth M, Eriksen J, Rasmussen JW, et al. Intestinal permeability of ${ }^{51} \mathrm{Cr}$-labelled ethylenediaminetetraacetic acid in patients with Crohn's disease and their first degree relatives. Scand $\mathcal{F}$ Gastroenterol 1989;24:993-8. 
5 Teahon K, Smethurst P, Levi AJ, et al. Intestinal permeability in patients with Crohn's diseas degree relatives. Gut 1992;33: $320-3$.

6 May G, Sutherland L, Meddings J. Is smal intestinal permeability really increased in relatives of patients with Crohn's disease? Gastroenterology 1993;104:1627-32.

7 Munkholm P, Langholz E, Hollander D, et al. Intestinal permeability in patients with Crohn's disease and ulcerative colitis and their first degree relatives. Gut 1994;35:68-72.

8 Yacyshyn BR, Meddings JB. CD45RO expression on circulating CD19+ B-cells in Crohn's disease correlates with intestinal permeability. Gastroenterology 1995;108:132-7.

9 Hilsden RJ, Meddings JB, Sutherland IR Intestinal permeability changes in response to Intestinal permeability changes in response to cetylic salicylic acid in relatives or patients 110:1395-403.

10 Pironi L, Miglioli M, Ruggeri E, et al. Effect of non-steroidal anti-inflammatory drugs on intestinal permeability in first degree relatives of patients with Crohn's disease [abstract]. Gas troenterology 1992;102:A679.

11 Söderholm JD, Olaison G, Lindberg E, et al. Different intestinal permeability patterns in relatives and spouses of patients with Crohn's disease: an inherited defect in mucosal defence? Gut 1999;44:96-100.

12 Zamora SA, Hilsden RJ, Meddings JB, et al. Intestinal permeability before and after ibuprofen in families of children with Crohn's disease. Can $\mathcal{F}$ Gastroenterol 1999;13:31-3.

\section{BOOK REVIEW}

Pancreatic Disease Towards the Year 2000. 2nd edn. Edited by Johnson CD, Imrie CW. (Pp 468; illustrated; £80.00.) Berlin: Springer Verlag, 1999. ISBN 1-85233-037-6.

This interesting book arises from a series of lectures held at a meeting in Glasgow. The editors have chosen a very ambitious title, Pancreatic Disease towards the Year 2000, which an impartial reader could interpret in two ways: either the book is a review of all pancreatic diseases or it throws light on the next century. Neither is the case. The editors of the book have not placed particular value on being comprehensive, but rather treat five areas emphasised at their meeting, all of which are of particular scientific interest at present-acute pancreatitis, transplantation, chronic pancreatitis, endocrine/exocrine interactions, and pancreatic cancer. There is a scientific focus and not merely a new rendering of current knowledge from $\mathrm{A}$ to $\mathrm{Z}$. The list of participants, identical with the list of authors, contains more than 80 names well known in the pancreatic literature. They come mostly from the United Kingdom or Germany. All reported on their specialis areas, which means that we are presented with current knowledge on each of these topics. The topics covered in each of the five areas are well balanced and representative, and include basic and clinical science as well as laboratory and clinical studies. This is equally true for the clinical studies that cover conservative and surgical treatment studies. Certain topics continually reappear in the literature and others only seldomly, so that the reader is grateful for attention the book gives to the latter-for example, "Management of Costs of the Most Severe Acute Pancreatitis" and "The Burden of Acute Pancreatitis", and in regard to pancreatitic cancers, "The Quality of Life Assessment".
At whom is this book directed? It is not a series of recipes for diagnosis and treatment. It is, however, an excellent reference work for all non-pancreatologists who wish to inform themselves about individual pancreatic diseases, their particular problems, and the current status of knowledge. It is also a very good book for pancreatologists who are undertaking a study or have to write a review and need to take into account the latest literature (up to 1997). I have added this book to my collection without hesitation.

P G LANKISCH

NOTES

\section{Sir Francis Avery Jones BSG Research Award 2000}

Applications are invited by the Education Committee of the British Society of Gastroenterology who will recommend to Council the recipient of the 2000 Award. Applications (TWENTY COPIES) should include:

- A manuscript (2 A4 pages ONLY) describing the work conducted

- A bibliography of relevant personal publications

- An outline of the proposed content of the lecture, including title

- A written statement confirming that all or a substantial part of the work has been personally conducted in the UK or Eire.

Entrants must be 40 years or less on 31 December 1999 but need not be a member of the BSG. The recipient will be required to deliver a 30 minute lecture at the Annual Meeting of the Society in March 2000. Applications (TWENTY COPIES) should be made to the Honorary Secretary, BSG, 3 St Andrews Place, London NW1 4LB, by 1 December 1999.

\section{What's New in Coloproctology}

The Lecture Course What's New in Coloproctology will be held at St Mark's Hospital, London, UK, on 11-13 October 1999. Further information from: The Administrator, $\mathrm{St}$ Mark's Academic Institute, St Mark's Hospital, Northwick Park, Harrow, Middlesex HA1 3UJ, UK. Tel: +44 181235 4046/8; Fax: +44 181235 4039; Email: e.power@ic.ac.uk

British Society of Gastroenterology Hopkins Endoscopy Price 2000

Applications are invited by the Endoscopy Committee of the British Society of Gastroenterology who will recommend to Council the recipient of the 2000 Award. The Award is given for a body of work which contributes to the discipline of endoscopy. Applications (TEN COPIES) should include:

- A manuscript (2 A4 pages ONLY) describing the work conducted

- A bibliography of relevant personal publications

- An outline of the proposed content of the lecture, including title
- A written statement confirming that all or a substantial part of the work has been personally conducted in the UK or Eire.

An applicant need not be a member of the BSG. The recipient will be required to deliver a 20 minute lecture at the Annual Meeting of the Society in March 2000. Applications (TEN COPIES) should be made to the Endoscopy Section Secretary, BSG, $3 \mathrm{St}$ Andrews Place, London NW1 4LB, by 1 December 1999.

\section{2th European Intensive Course of} Digestive Endoscopy

The 12th European Intensive Course of Digestive Endoscopy will be held in Strasbourg, France, on 3 and 4 December 1999. Further information from: MCC, Michèle Centonze Conseil, 6 Bis rue des Cendriers, 75020 Paris, France. Tel: (+)33 (0)1 446268 80; Fax: (+)33 (0)1 434968 58; Email: mail@m-centonze-conseil.com

\section{CORRECTIONS}

A footnote was inadvertently omitted from the paper by Yang et al (Gut 1999;44:51926). The footnote reads as follows: Drs Yang and Plevy contributed equally to this work.

An error has come to light in the review by Wong et al (Gut 1999;44:890-5). On page 892 , column 1, paragraph 2, "In general TFF1 is associated with MUC6 expression, TFF2 with MUC5AC and TFF3 with MUC2 (Longman et al, personal communication)" should read "In general TFF1 is associated with MUC5AC expression, TFF2 with MUC6 and TFF3 with MUC2 (Longman et al, personal communication)". The authors regret any confusion this may have caused.

Several errors occurred in the leading article by Frayling (Gut 1999;45:1-4). On page 2, column 2, paragraph 1, "If it pairs with thymine, a G6A mutation will result" should read "If it pairs with thymine, a $\mathrm{G} \rightarrow \mathrm{A}$ mutation will result". Page 2 , column 2 , paragraph 2, "However, it may help us understand why loss of MMR is advantageous to a tumour cell, although there is an indication why the loss of one MMR allele might be an advantage" should read "However, it may provide a bridge in our understanding as to why the loss of MMR is actually an advantage to a tumour cell, though there are no clues, as yet, as to why loss of one MMR allele might be advantageous". Page 3, column 2, final paragraph, "Early studies used a bank of up to a dozen different microsatellites, mostly (CA)n repeats, which were often chosen semi-randomly and carefully to avoid issues of bias due to allelic loss in tumours" should read "Early studies used a bank of up to a dozen or so different microsatellites, mostly (CA)n repeats, often chosen semi-randomly, sometimes chosen carefully to avoid issues of bias due to allelic loss in tumours". 